\title{
AVALIAÇÃO DO USO DA PERFILAGEM GEOFÍSICA PARA RECONHECIMENTO E DETERMINAÇÃO DE ESPESSURAS DE CAMADAS DE CARVÃO EM DEPÓSITOS DO RIO GRANDE DO SUL
}

\author{
EVALUATION OF THE USE OF GEOPHYSICAL PROFILES FOR RECOGNITION AND \\ DETERMINATION OF COAL LAYERS THICKNESSES IN DEPOSITS OF RIO GRANDE DO \\ SUL, SOUTHERN BRAZIL
}

\section{Breno GORELIK, George Olufunmilayo GASPER, Paulo SALVADORETTI, Douglas Sander Quatiabara LIBARDI, Tiago de ALMEIDA, João Felipe Coimbra Leite COSTA \\ Universidade Federal do Rio Grande do Sul. Avenida Bento Gonçalves, 9500 - Porto Alegre - Rio Grande do Sul, Brasil. Email: brenogorelik@hotmail.com; gee_mail@yahoo.com; paulo.salvadoretti@ufrgs.br; quatiabara@gmail.com; almeida.geologia@gmail.com; : jfelipe@ufrgs.br}

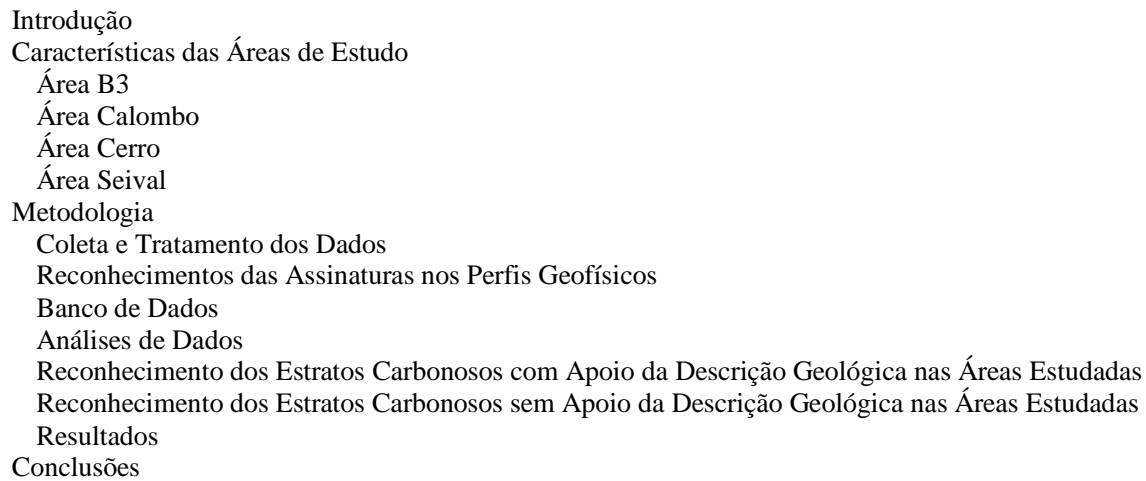

Reconhecimento dos Estratos Carbonosos com Apoio da Descrição Geológica nas Áreas Estudadas Reconhecimento dos Estratos Carbonosos sem Apoio da Descrição Geológica nas Áreas Estudadas Resultados

\begin{abstract}
RESUMO - Este estudo investiga a possibilidade do uso da perfilagem geofísica de gama natural e resistividade na discriminação de estratos carbonosos, em relação a outras litologias presentes em quatro depósitos de carvão localizados no Rio Grande do Sul (áreas B3, Calombo, Cerro e Seival). Uma vez observada a possibilidade de identificação dos estratos carbonosos com estes dois perfis geofísicos apenas, fez-se uma verificação da acuracidade na determinação das espessuras das camadas de carvão. Neste contexto, as espessuras das camadas de carvão foram comparadas com as espessuras observadas em testemunhos de sondagem, sendo que o reconhecimento das assinaturas das camadas pode ser feito com boa acuracidade para todos os depósitos, exceto no depósito do Cerro, onde o sinal do carvão confunde-se com o sinal de arenitos, inviabilizando muitas vezes a discriminação. Ressalte-se a importância deste tipo de avaliação, especialmente quanto às espessuras de camadas de carvão no planejamento de mina de curto prazo, onde não é exequível a sondagem com recuperação de testemunhos em bancadas de lavra simultaneamente ao processo extração de carvão, em função da demora da atividade de sondagem e custos elevados.
\end{abstract}

Palavras-chave: Perfilagem, geofísica, carvão.

\begin{abstract}
The study investigates the possibility of using geophysical well logging of natural gamma and resistivity in the identification of carbonaceous strata in relation to other lithologies present in four coal deposits located in Rio Grande do Sul (B3, Calombo, Cerro and Seival). Once the possibility of identification of the carbonaceous strata with these two geophysical profiles was observed, a verification of the accuracy in the determination of the thicknesses of the coal seams was performed. In this context, the thicknesses of the coal seams were compared with the thicknesses observed in recovered core samples and the recognition of the signatures of the seams was possible with good accuracy for all deposits, except in the Cerro deposit, where the signature of the coal was confused with the signature of sandstones, often making it impossible to discriminate. It should be stressed the importance of this type of evaluation, especially regarding the thickness of coal seams in the short-term mine planning, where drilling with core sample recovery is not feasible simultaneously with the extraction process, due to the delays in drilling and high costs.
\end{abstract}

Keywords: Well logging, geophysics, coal.

\section{INTRODUÇÃO}

A técnica de perfilagem geofísica é bastante usada na mineração de carvão, em especial, por sua capacidade de discriminar estratos carbonosos e pela potencialidade na substituição das análises laboratoriais feitas para determinados parâmetros físicos e químicos, de interesse na elaboração de projetos de lavra e beneficiamento de carvão.

Análises laboratoriais são, geralmente, efetivadas a partir de amostras obtidas por sondagem rotativa com recuperação de testemunhos, enquanto que a perfilagem 
geofísica é executada ao longo de furos não necessariamente feitos com essa finalidade.

A perfilagem registra variações de propriedades das rochas interceptadas pelos furos e, eventualmente, mostra registros que se correlacionam com as litologias presentes no depósito. Assim, nas condições adequadas, essa técnica é capaz de identificar contrastes de propriedades físicas e químicas das rochas, podendo ser usada para estimar características físicas e químicas e ajudar a delinear corpos de minério.

No caso de depósitos de carvão, a perfilagem serve para delinear as interfaces carvão/estéril (Hoffman et al., 1982; Borsaru \& Asfahania, 2007), auxiliando no estabelecimento da correlação estratigráfica e, eventualmente, para gerar estimativas de parâmetros de qualidade e de comportamento geomecânico. No planejamento de produção de mina no curto prazo, em virtude da impossibilidade de operacionalização da sondagem testemunhada, pode-se executar a perfilagem geofísica em furos de desmonte de rocha, como alternativa para obtenção de contatos litológicos e as demais estimativas acima citadas.

Diversos perfis geofísicos registram contrastes existentes entre carvão e os materiais estéreis adjacentes, notadamente os perfis de gama natural, resistividade, sônica, densidade e nêutrons (Hoffman et al., 1982; Hearst et al., 2000). Aspectos negativos quanto ao uso dos perfis de densidade e nêutrons relacionam-se à necessidade de emprego de fontes radioativas nessas sondas (Césio 137 para densidade e Amerício - Berílio para nêutrons).

Segundo Kayal \& Das (1981), a resistividade do carvão varia com o grau de carbonização (rank). Assim, Kayal \& Das (1981) basearam seu trabalho em carvões indianos subbetuminosos a betuminosos. Eles investigaram a existência de correlação entre teor de cinzas e os registros de gama natural ou resistividade. $\mathrm{O}$ contraste de resistividade observado na perfilagem geofísica de carvão, conforme esses estudos, seria capaz de refletir as variações no teor de cinzas (Bond et al., 1971). No entanto, para vários depósitos, incluindo-se os do Rio Grande do Sul, isso não ocorra de forma muito clara.

Para esses autores, a resistividade aumenta com a redução do teor de cinzas presente nas camadas de carvão de um mesmo rank. Kayal \& Das (1981) reconheceram, em seu trabalho, que a contagem da radiação gama natural aumenta com o aumento de folhelhos (cinzas) intercalados no carvão. Diferentemente da resistividade, a contagem gama independe da saturação de água.

Baseando-se nesses fatos, eles elaboraram gráficos combinando registros de resistividade e gama natural, com a finalidade de estimar teores de cinza.

Os dados provenientes das camadas de carvão apresentaram uma forte correlação entre resistividade e gama natural: maior teor de cinzas implicava maior contagem de gama e menor resistividade.

Nos depósitos de carvão brasileiros, especificamente no Rio Grande do Sul, também se observa boa correlação entre massa específica, cinza e poder calorífico, como se verifica em relatos de aplicação do density log (Webber et al., 2006, 2008).

Entretanto, o uso do density log, assim como ocorre com os demais perfis, ainda não se popularizou no RS, em função de diversos fatores, entre eles o pequeno número de mineradores de carvão existentes no estado (o que leva à ausência de equipes de perfilagem que disponibilizam essa sonda).

Também a inexistência de uma infraestrutura adequada para manuseio/armazenamento de fontes radioativas nas empresas interessadas tornou-se um problema. Dessa forma, os trabalhos de perfilagem, quando executados no Brasil, fazem uso das sondas gama natural e resistividade, preferencialmente.

Diante do exposto, este estudo apresenta como meta principal investigar o uso de perfilagem geofísica de gama natural (GN) e resistividade (RES) na discriminação de estratos carbonosos, em relação às demais litologias presentes em algumas áreas de interesse no RS.

Caso exista a possibilidade de identificar os estratos carbonosos, uma meta secundária de interesse imediato é avaliar o grau de acuracidade na determinação das espessuras das camadas de carvão, inferindo também a capacidade de discriminar estratos carbonosos de pequena espessura com sensores de GN e RES nas áreas em estudo. 


\section{CARACTERÍSTICAS DAS ÁREAS DE ESTUDO}

Este estudo foi realizado em quatro áreas do $\mathrm{RS}$, indicadas no mapa apresentado na figura 1, e assim denominadas: Área B3, Área Calombo, Área Cerro e Área Seival. Detalhes de cada uma destas áreas estão descritos a seguir.

\section{Área B3}

A Área B3 localiza-se no município de Butiá, distante $86 \mathrm{~km}$ da capital Porto Alegre (RS), e sua extensão é de aproximadamente 221 hectares. A Formação Rio Bonito, unidade litoestratigráfica de idade Permocarbonífera, é a principal unidade desta área, pois nela está inserido o pacote carbonoso de interesse econômico. Litologicamente, a Formação Rio Bonito é constituída por siltitos, argilitos e folhelhos, com intercalações de camadas de carvão pertencentes à fácies de topo da Formação. Na base desse pacote predominam paraconglomerados e arenitos grosseiros (Milani, 1997). O pacote carbonoso em B3 é composto por quatro camadas de carvão principais, denominadas A, S, M1/M2 e I1, alcançando uma espessura total aproximada de 21 metros (incluindo-se as litologias estéreis intermediárias). O perfil geológico médio da Área B3 é apresentado na figura 2 (à esquerda), sendo que a espessura média de rochas estéreis (cobertura) sobre a Camada A varia de 25 a 35 metros (Gorelik, 2014).

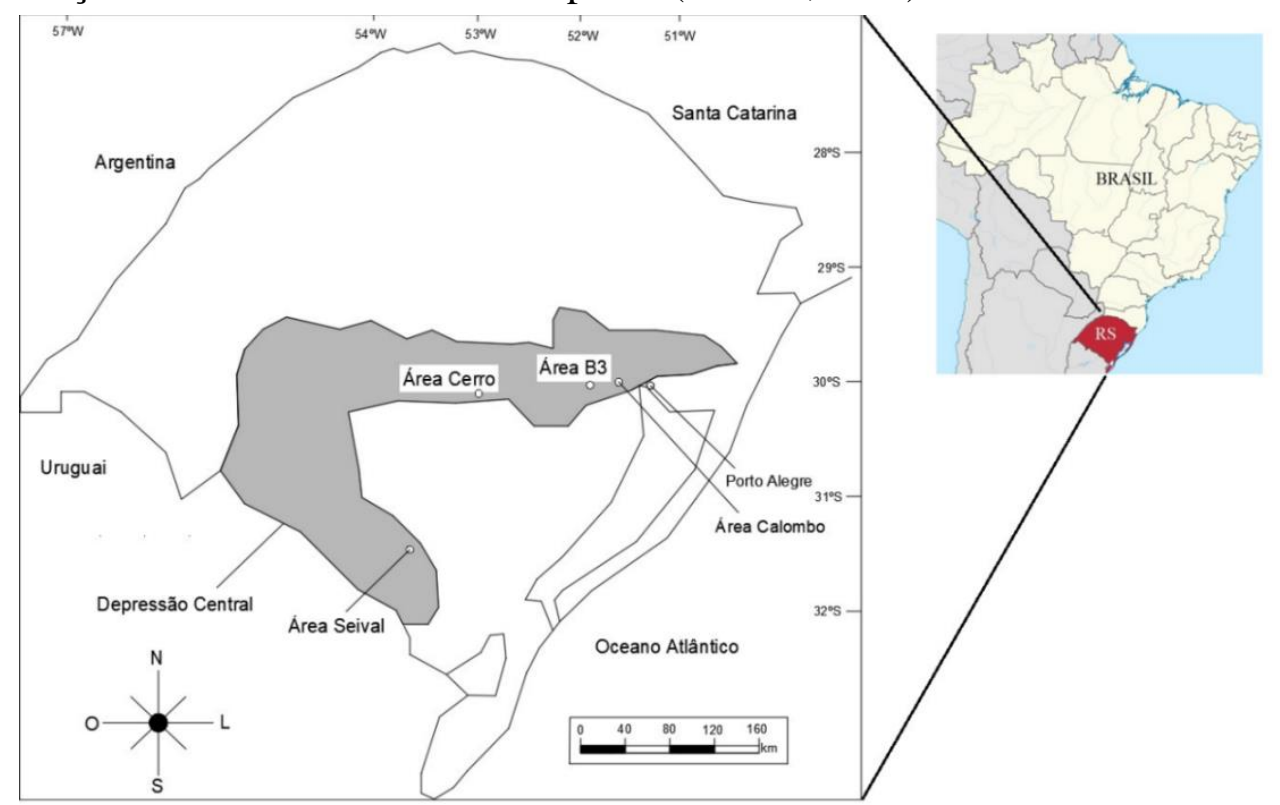

Figura 1 - Localização das áreas de estudo, situadas no Estado do Rio Grande do Sul.

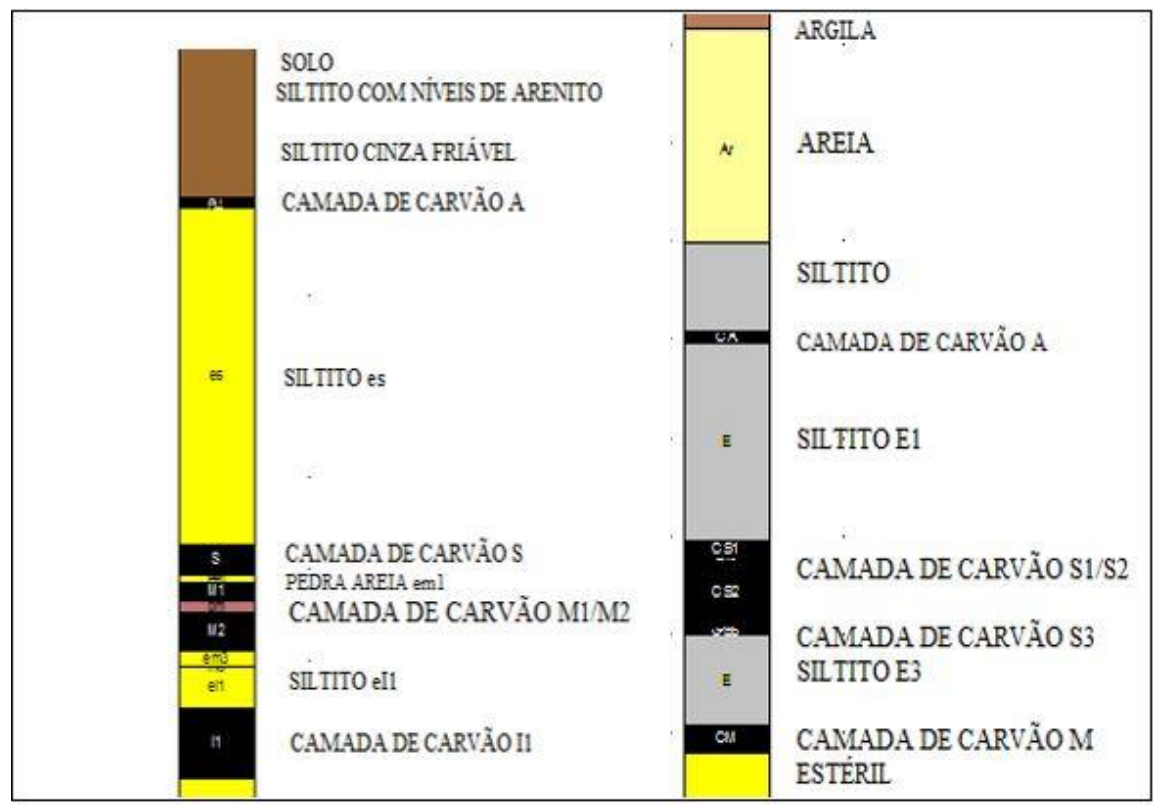

Figura 2 - Coluna litológica típica dos depósitos localizados na Área B3 (à esquerda) e na Área do Calombo (à direita). 


\section{Área Calombo}

Esta região situa-se a uma distância de $56 \mathrm{~km}$ de Porto Alegre, em direção oeste, no município de Arroio dos Ratos. A área pesquisada compreende uma superfície de aproximadamente 113 hectares.

A geologia local apresenta como elemento principal a Formação Rio Bonito, que contém o pacote carbonoso de interesse. Aqui a Formação Rio Bonito é representada por sedimentos pelíticos (siltitos, lamitos) e camadas de carvão. Em direção à base, ocorrem paraconglomerados e arenitos estratificados.

No topo dessa unidade ocorrem as camadas de carvão, em um pacote carbonoso principal com espessura média de $20 \mathrm{~m}$ (incluindo as camadas intermediárias de estéril). No pacote estão presentes as camadas de carvão assim denominadas, do topo para a base: A, S1, S2, S3 e M (Gorelik, 2014). O perfil geológico típico é apresentado na figura 2 (à direita).

\section{Área Cerro}

A Área Cerro localiza-se no município de Cachoeira do Sul, distante $220 \mathrm{~km}$ de Porto Alegre, compreendendo uma área total de pesquisa de aproximadamente 228 hectares.

A formação geológica que contém os estratos de carvão de interesse é a Formação Rio Bonito. As camadas de carvão presentes na área são assim denominadas: Camada Superior (S), Média (dividida em três bancos M1, M2 e M3) e Inferior (dividida em dois bancos I1 e I2).

O pacote carbonoso total (incluindo os estratos estéreis intermediários) atinge uma espessura aproximada de 32 metros. A cobertura de estéril sobreposta à camada $S$ é representada por um banco de arenito e siltito no contato superior, com espessura média de 21 metros (Gorelik, 2014). O perfil geológico típico é apresentado na figura 3.

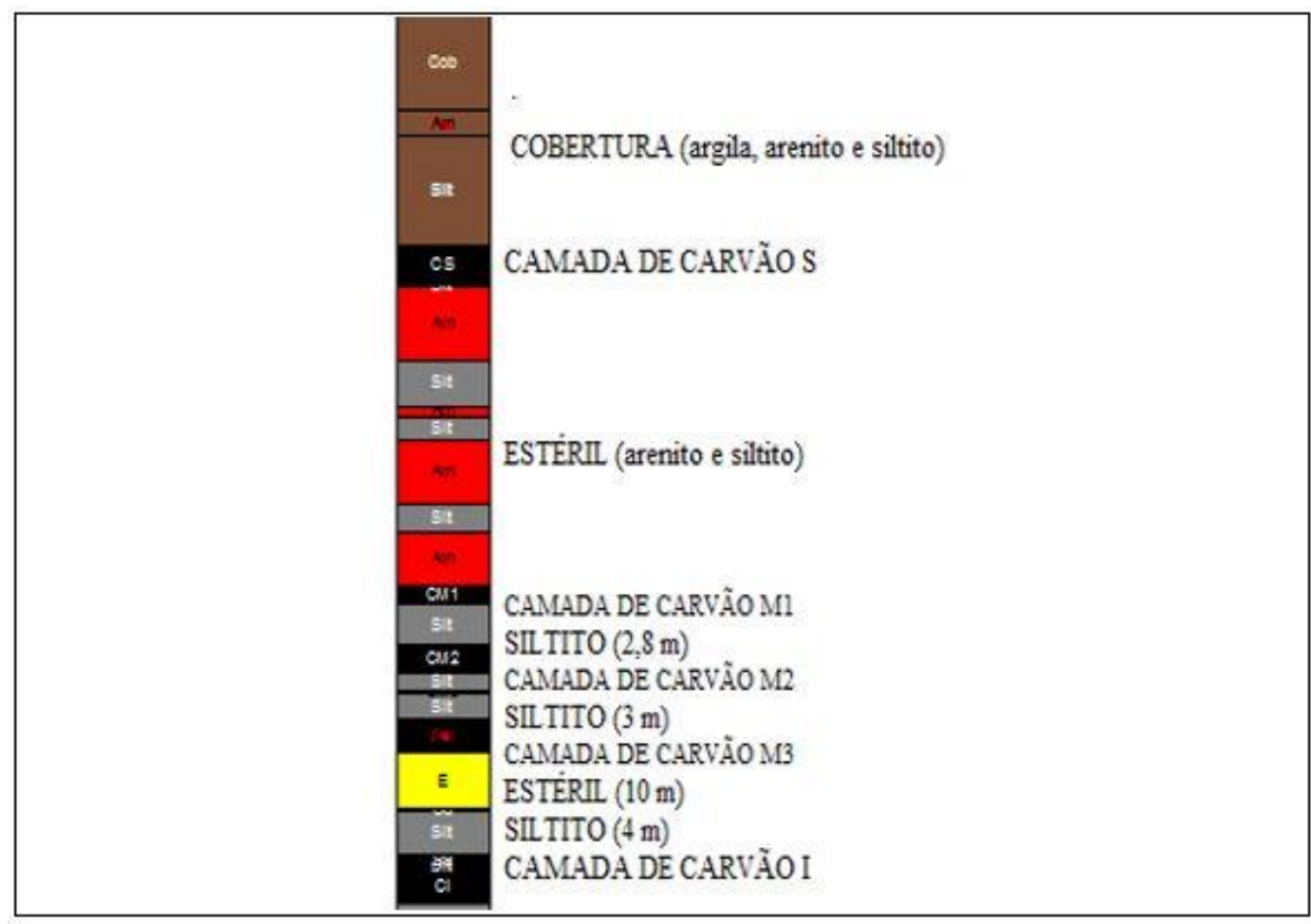

Figura 3 - Coluna litológica típica do depósito do Cerro.

\section{Área Seival}

A área de estudo Seival localiza-se no município de Candiota, distante $300 \mathrm{~km}$ de Porto Alegre, e apresenta extensão aproximada de 1.890 hectares.

A Formação Rio Bonito, que contém os estratos de carvão de interesse econômico, mostra basicamente uma alternância de arenitos finos, localmente médios a grosseiros (conglomeráticos) e horizontes pelíticos com camadas de carvão. A espessura desta formação, considerando-se as regiões onde se desenvolve todo o pacote, é da ordem de $60 \mathrm{~m}$, sendo uma característica importante a homogeneidade, com raras variações.

A Formação Rio Bonito apresenta três horizontes pelíticos com camadas de carvão, separados entre si por arenitos finos e leitos carbonosos, decorrentes das mudanças do ambiente deposicional. O horizonte pelítico- 
carbonoso inferior é composto por quatro camadas de carvão (I4, I3, I2, I1) separadas entre si por siltitos.

A espessura total desse horizonte é da ordem de 5 a $7 \mathrm{~m}$. No horizonte pelítico-carbonoso intermediário, em direção ao topo da Formação Rio Bonito, destaca-se o horizonte "Candiota", que é o mais importante sob o ponto de vista de explotação de carvão mineral. A camada Candiota compõe-se de dois bancos de carvão: Candiota Superior (CS), com espessura de 2 a $3,2 \mathrm{~m}$, e Candiota Inferior (CI), com espessura de 1,30 a 2,30 m, separados entre si por litologias estéreis.

O terceiro pacote pelítico (pacote superior) é composto por quatro camadas de carvão (S3, S4, S5 e S6), localmente ocorrendo uma quinta camada (S7). Estas camadas possuem espessuras individuais de 1 a $2 \mathrm{~m}$, separadas por siltitos, perfazendo 7 a $8 \mathrm{~m}$ de espessura (Gorelik, 2014).

$\mathrm{Na}$ Área Seival, a cobertura de estéril sobreposta ao pacote superior varia entre $10 \mathrm{~m} \mathrm{e}$ $60 \mathrm{~m}$, aproximadamente, apresentando os estratos S6 e S7 muitas vezes erodidos. O perfil geológico característico é mostrado na figura 4. A figura 5 apresenta testemunhos de sondagem obtidos em Seival (a cor negra caracteriza os estratos de carvão).

Atualmente, das quatro áreas referidas acima, B3 encontra-se em operação (reserva remanescente de 5 milhões de toneladas), Calombo encerra a produção em 2018 (reservas esgotadas), Cerro (reserva remanescente de 90 milhões de toneladas) e Seival (recursos totais de 600 milhões de toneladas) aguardam para entrar em atividade.

As atividades são conduzidas pela empresa COPELMI MINERAÇÃO Ltda., que é uma empresa nacional voltada essencialmente à produção de carvão mineral para consumo no mercado termoelétrico. Trata-se da maior mineradora privada de carvão no Brasil, abastecendo em torno de $20 \%$ do total do mercado de carvão mineral nacional a partir de jazidas localizadas no Rio Grande do Sul (Anon, 2017).

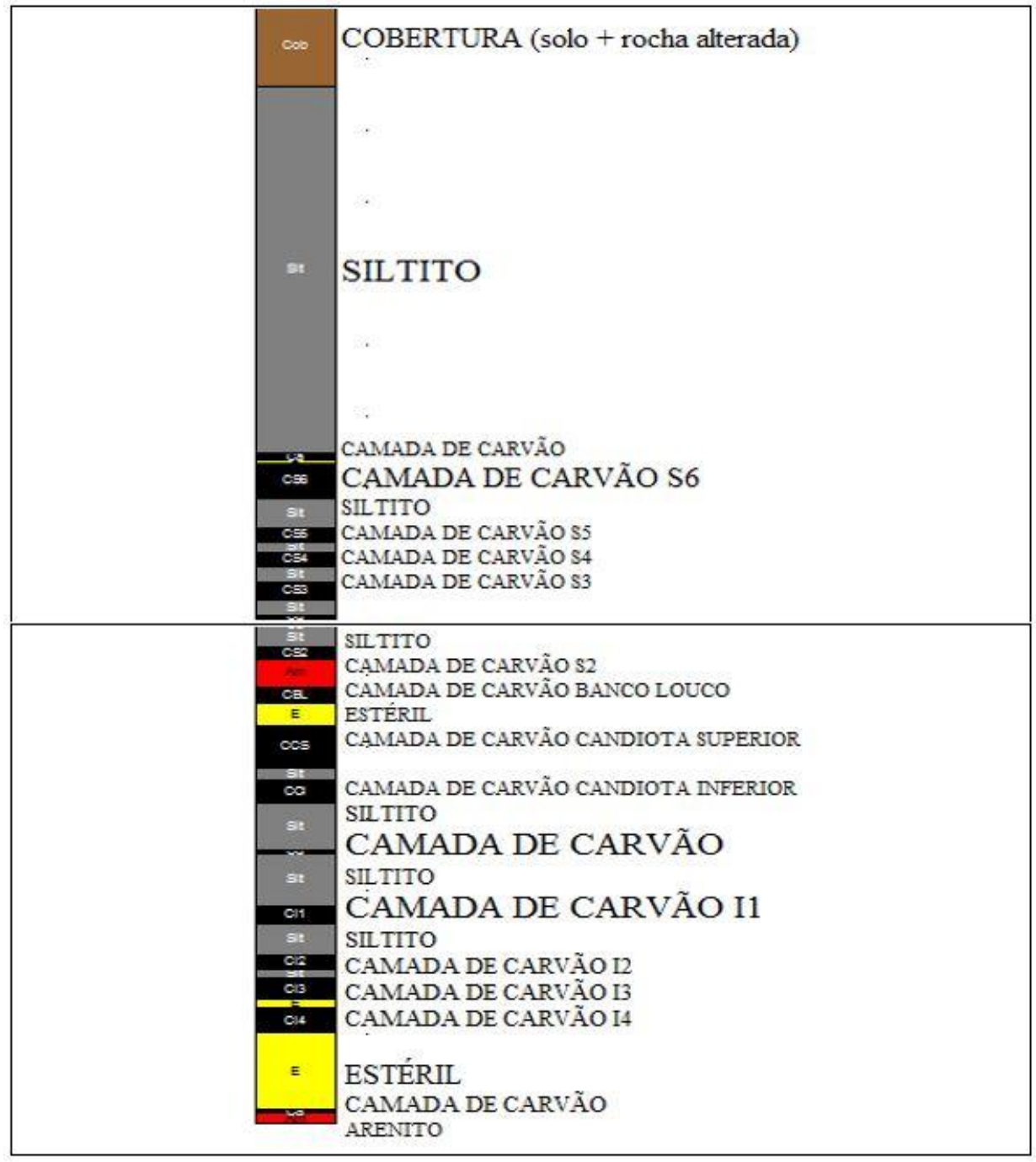

Figura 4 - Coluna litológica típica do depósito de Seival. 


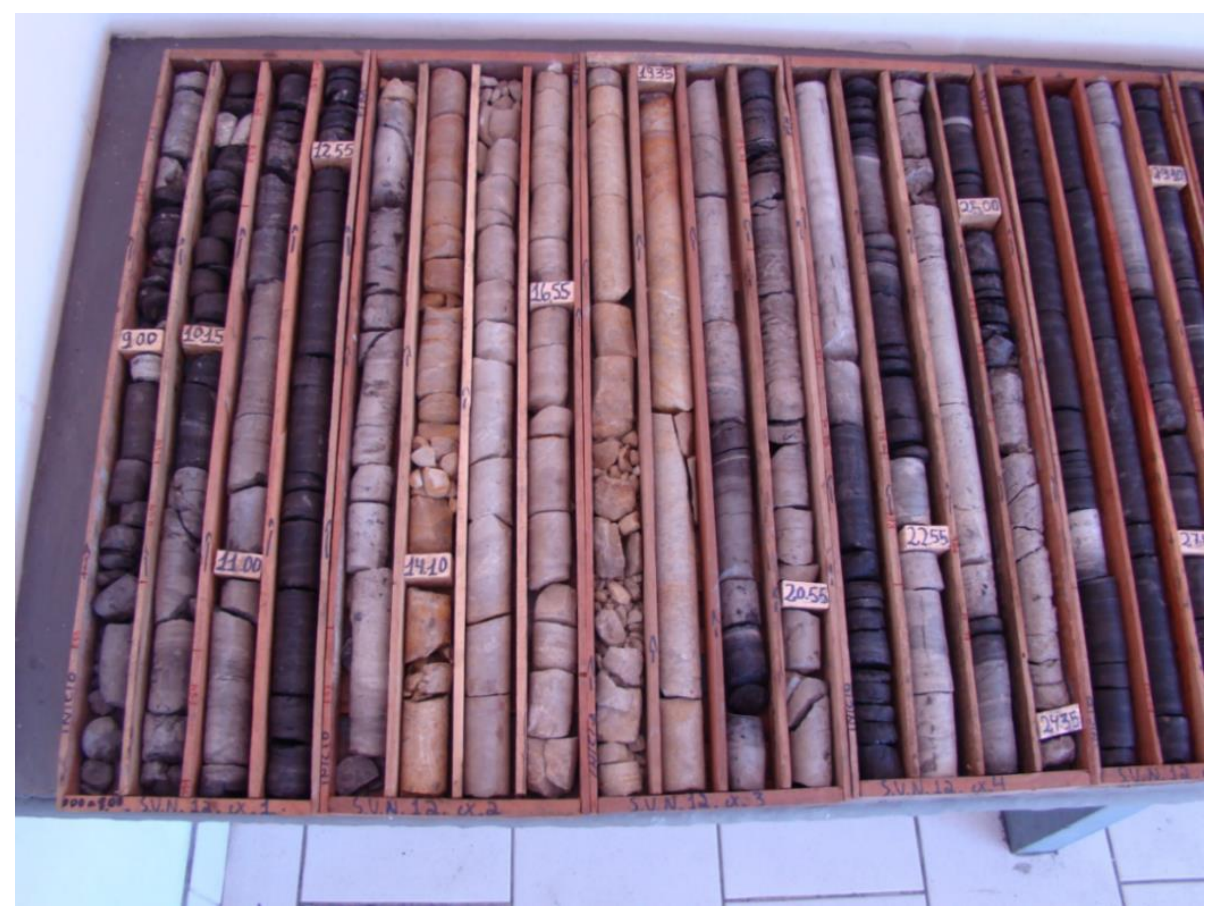

Figura 5 - Caixas de testemunhos de sondagem contendo as litologias presentes no depósito de depósito de Seival.

\section{METODOLOGIA}

A metodologia empregada para atingir as metas propostas foi:

i - Acompanhar campanhas de sondagem com recuperação de testemunho e posterior análise química do material recuperado, objetivando ter visão do processo como um todo, suas limitações e fontes de erro;

ii - Realizar a perfilagem geofísica em campo;

iii- Estudar os registros geofísicos e observar se existem "assinaturas" características dos estratos carbonosos que permitem sua identificação;

iv - Estabelecer regras para a definição de espessuras das camadas de carvão, verificando as particularidades e os cuidados envolvidos nessa operação;

$\mathrm{v}$ - Estimar a acuracidade na determinação das espessuras das camadas comparando com a descrição da sondagem testemunhada.

O trabalho realizado no campo consistiu na perfilagem de diversos furos de sondagem vertical com profundidades variadas (entre $35 \mathrm{e}$ 75 metros). Os furos interceptam as principais camadas de carvão dos depósitos de interesse, sendo que a classificação das camadas foi feita com base na correlação estratigráfica definida pelo setor de geologia da empresa COPELMI MINERAÇÃO Ltda., por meio da descrição dos testemunhos de sondagem.

O reconhecimento das litologias está baseado na análise visual da textura, estrutura e composição dos mesmos. No caso de carvões, são descritas, detalhadamente, as características qualitativas, tais como, o conteúdo de vitrinita, seguindo o padrão da Standards Association of Australia (Anon,1993). Havendo intercalações dentro da camada de carvão, o geólogo ainda descreve quais os tipos de impurezas presentes.

\section{Coleta e Tratamento dos Dados}

O tratamento dos dados obtidos nas quatro áreas pesquisadas foi dividido em dois grupos: tratamento dos dados obtidos por sondagem com recuperação de testemunhos e tratamento dos dados obtidos por perfilagem geofísica. Os dados coletados nos registros de perfilagem foram interpretados visualmente na tela do computador ou, quando necessário, impressos, respeitando as diferenças nos parâmetros para cada litologia.

Não foram feitas correções de diâmetro de furo e presença de fluido nos perfis geofísicos de GN e RES, de modo que se usaram os registros brutos, apenas suavizados por média móvel (10 a 15 pontos, em geral) e reposicionados por deslocamento vertical (shift) quando necessário, para melhor concordância com os testemunhos de sondagem.

Para proporcionar confiabilidade ao trabalho de reconhecimento das assinaturas das litologias, foram selecionados furos que apresentassem $100 \%$ (ou muito próximo disso) de recuperação do testemunho de sondagem. 


\section{Reconhecimentos das Assinaturas nos Perfis Geofísicos}

Para o reconhecimento das assinaturas das camadas de carvão em cada depósito, procedeuse de duas maneiras diferentes: a primeira usando os dados de sondagem com recuperação de testemunho para confrontar esses dados com os intervalos das camadas de carvão identificados na perfilagem. As figuras 6 a 9 apresentam exemplos desta análise comparativa nos furos dos depósitos estudados. A segunda, mostrada nas figuras 10 (a) e (b), identificando os intervalos que presumivelmente apresentavam sinais de carvão, mas sem a informação da descrição geológica, seguido pelo cruzamento com a descrição geológica para avaliar o possível erro.

Para a determinação da espessura das camadas de carvão foi adotada uma das possíveis metodologias descritas em Hoffman et al. (1982), método baseado em testes empíricos (ratio method) envolvendo os perfis geofísicos e testemunhos de sondagem, no qual se estima a distância (valor da anomalia) entre a resposta do carvão e a da rocha estéril produzida em um determinado contato. Posteriormente é designada uma fração dessa distância como sendo a profundidade daquele contato. No caso presente, a fração designada é $20 \%$, e foi aplicada tanto para o perfil de gama natural quanto para resistividade. Quando não houve boa coincidência entre a profundidade do contato definida por GN e por RES, foi adotado o valor definido por RES, o que provou ser essa a forma de gerar as melhores estimativas de espessuras de camadas. É importante notar que em alguns casos foram aplicados deslocamentos verticais nos registros de perfilagem, para melhor correlação com as amostras de sondagem.

Como exemplo de análise comparativa nas áreas de estudo, os estratos M1 e M2 (Figura 6) possuem espessuras iguais a $0,58 \mathrm{~m}$ e $0,75 \mathrm{~m}$, conforme a descrição de testemunhos de sondagem. Por perfilagem, as espessuras foram estimadas em $0,60 \mathrm{~m}$ e $0,78 \mathrm{~m}$.

$\mathrm{O}$ estrato $\mathrm{CM}$, conforme os testemunhos de sondagem, possui espessura igual a $1,12 \mathrm{~m}$ (Figura 7). Por perfilagem, a espessura foi estimada em $1,09 \mathrm{~m}$.

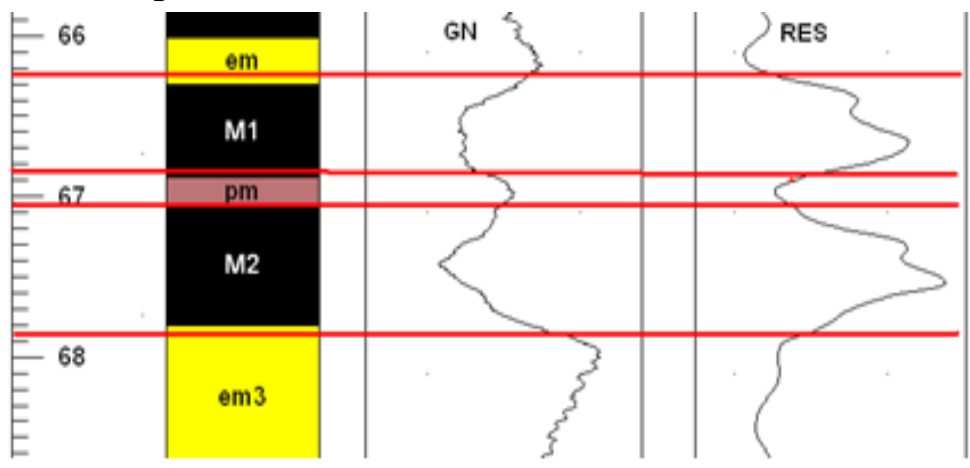

Figura 6 - Exemplo de valores encontrados por perfilagem, comparados com a descrição geológica do furo B3-29.

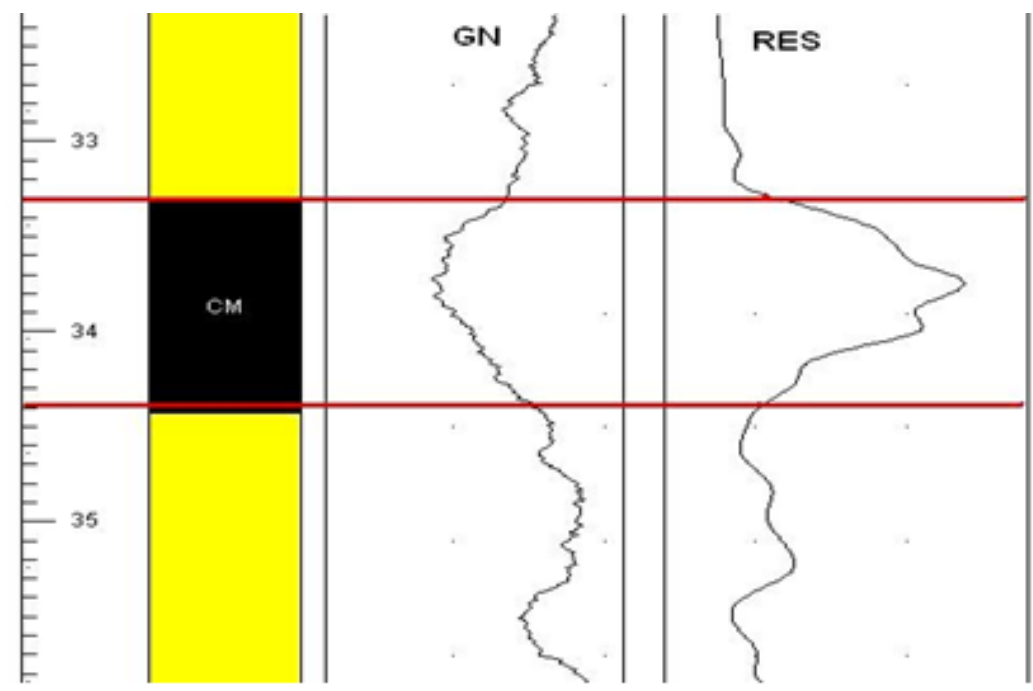

Figura 7 - Exemplo de valores encontrados por perfilagem e comparados com a descrição geológica do furo CAL-15. 


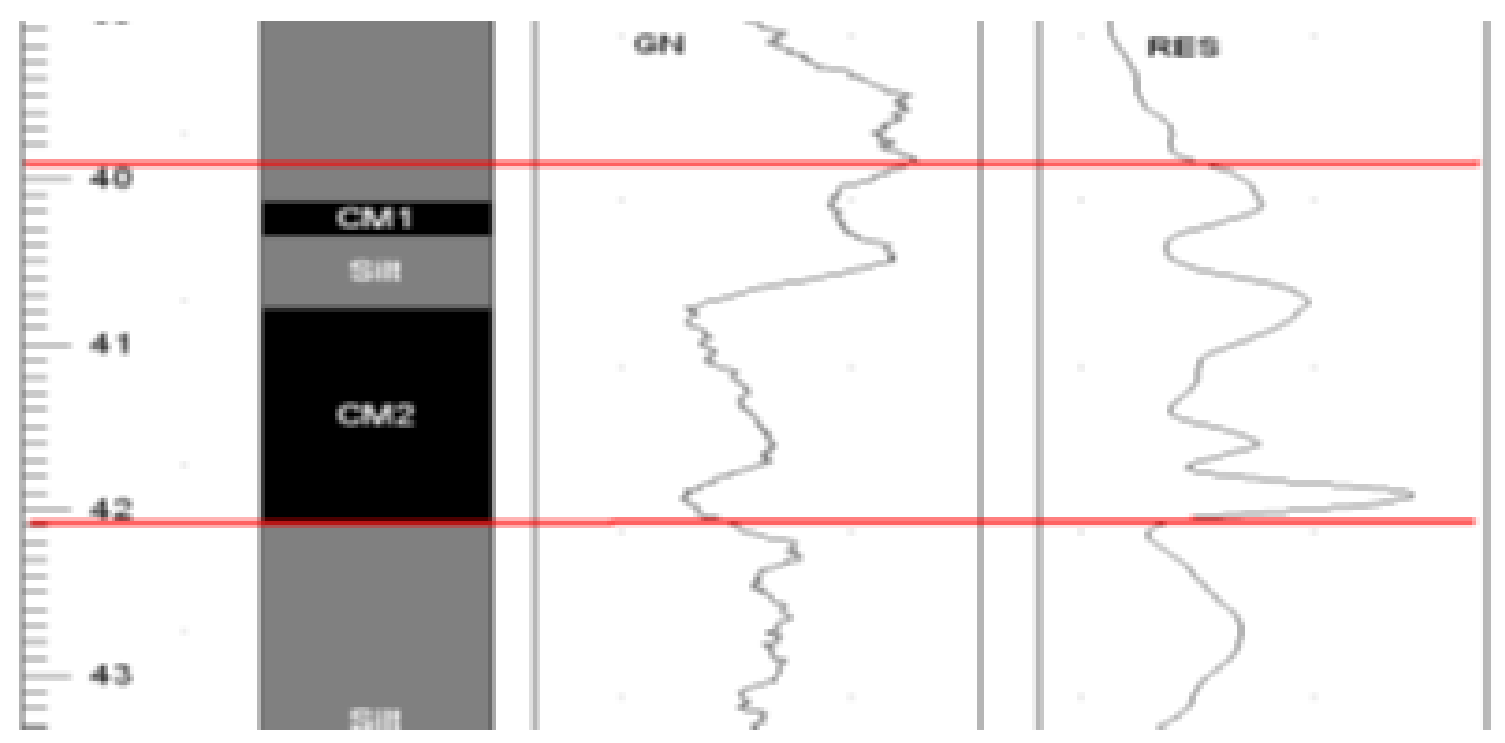

Figura 8 - Exemplo de valores encontrados por perfilagem, comparados com a descrição geológica do furo CRN-33.

A soma de espessuras dos estratos M1 e M2, incluindo o siltito intermediário, resultam em uma espessura total de 1,92m (Figura 8), de acordo com os testemunhos de sondagem. $\mathrm{Na}$ perfilagem, a espessura total estimada foi de 2,20m. O estrato CS6, de acordo com as amostras de sondagem, possui espessura igual a 2,09m (Figura 9). A espessura da camada foi estimada em 2,10m com base em dados de perfilagem. A figura 9 apresenta também, na parte superior, uma tentativa de definição de uma porção de estéril (E), e de uma camada pouco espessa de carvão $(\mathrm{Ca})$, esta última mostrando contraste pobre de resistividade e sem sinal de GN. $\mathrm{Na}$ porção inferior da ilustração, uma intercalação de siltito carbonoso com espessura 0,08m (conforme descrição de testemunho) está assinalada por uma seta no perfil de resistividade.

A soma das espessuras dos estratos $\mathrm{S} 1, \mathrm{~S} 2$, $\mathrm{S} 3 \mathrm{e}$ as intercalações de siltitos resultam em um total de 4,50m (20,15m - 24,65m), conforme as amostras de sondagem (Figura 10). Na perfilagem, a espessura total estimada foi de $4,45 \mathrm{~m}$. Na figura $10(\mathrm{~b})$, a camada $\mathrm{M}$ apresenta $1,22 \mathrm{~m}$ pela sondagem, enquanto a perfilagem mostra $1,15 \mathrm{~m}$. A parte inferior da camada I1, com $0,65 \mathrm{~m}$, é suficientemente espessa para ser detectada pela perfilagem, estimada em $0,70 \mathrm{~m}$.

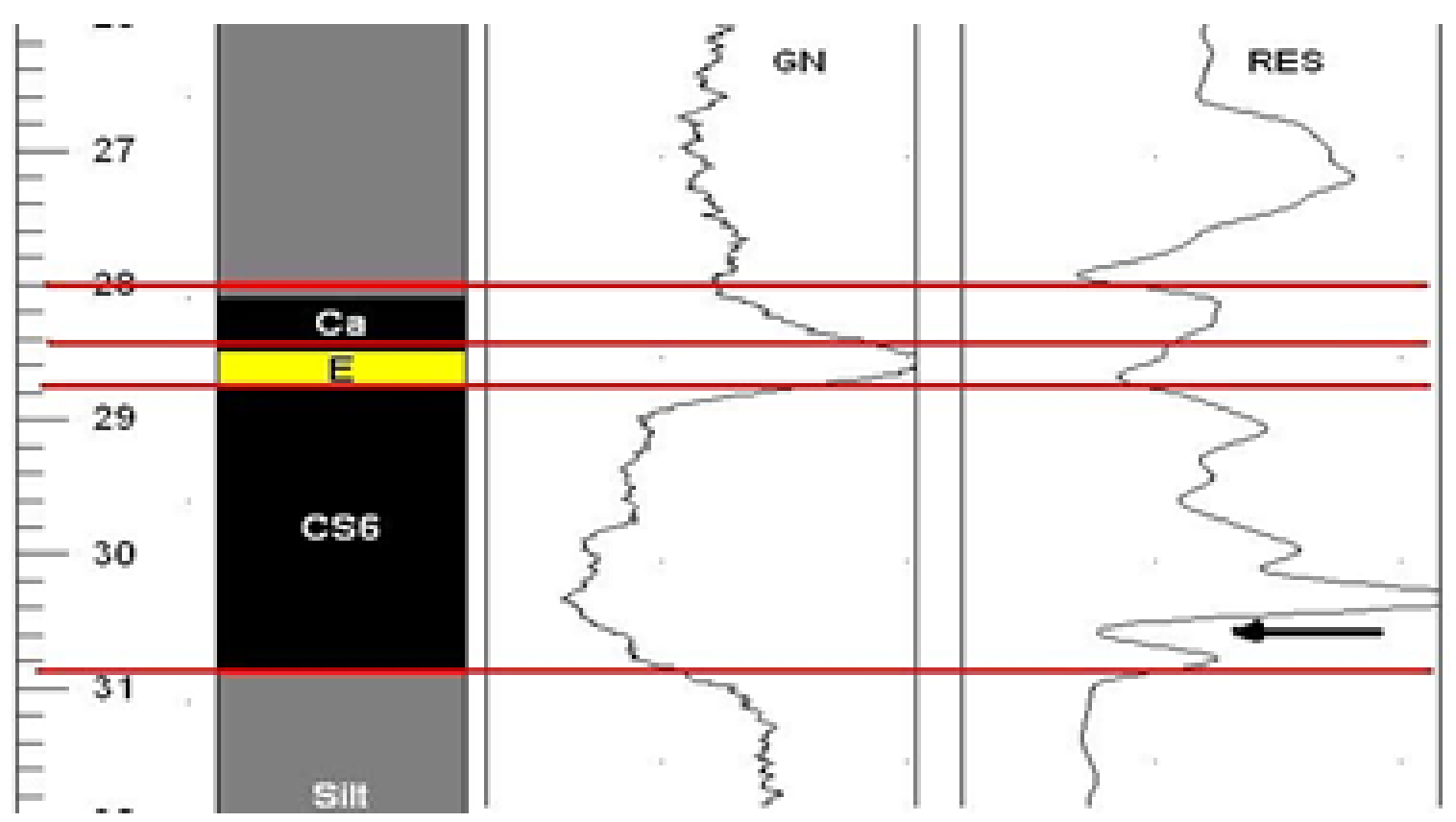

Figura 9 - Exemplo de valores encontrados por perfilagem e comparados com a descrição geológica do furo SVN-15. 
A análise dos perfis geofísicos e descrições litológicas permitiu visualizar que ao menos três áreas (B3, Cerro e Seival) apresentam algumas feições próprias que auxiliam bastante na individualização dos depósitos e, naturalmente, no reconhecimento dos estratos carbonosos por perfilagem.

No caso de B3, é o conjunto M1/M2 que aparece em geral bastante espesso, produzindo assinatura característica, sendo M2 com baixo conteúdo de cinzas.

Entretanto, pode eventualmente haver o

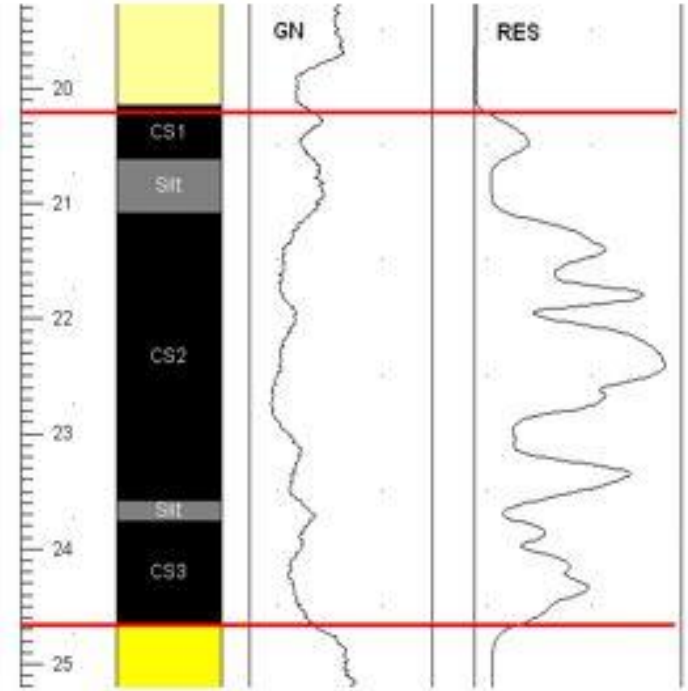

(a) aparecimento da camada I1, cuja assinatura geofísica é bastante semelhante ao conjunto M1/M2 (Figura 11). Essa ocorrência determina um grau maior de dificuldade para reconhecimento e definição adequados dos estratos carbonosos.

No Cerro ocorre um padrão frequente de arenito em contato com as camadas de carvão. Em Seival, as camadas Candiota Inferior e Candiota Superior aparecem com dimensões bem superiores aos demais estratos carbonosos que fazem parte do perfil geológico.

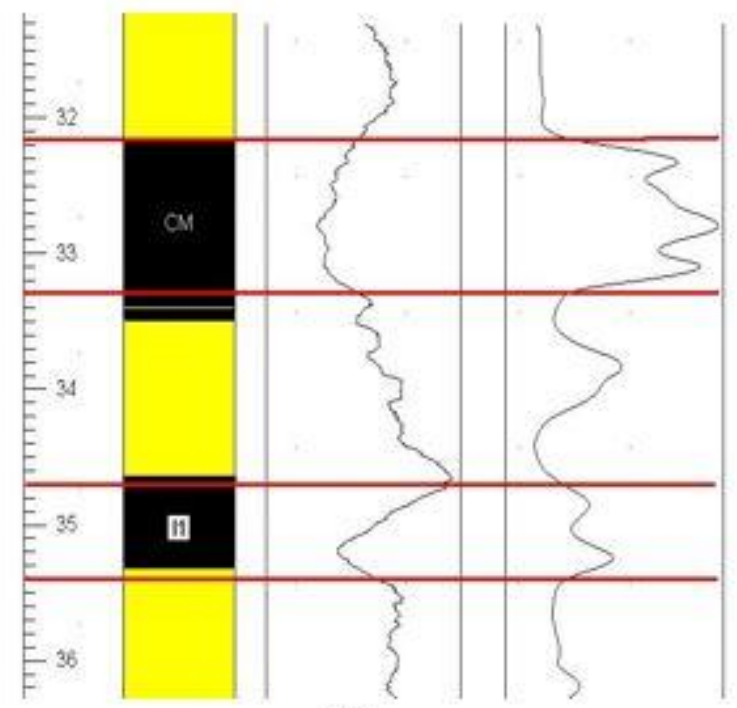

(b)

Figura 10 - (a) e (b). Exemplos de valores encontrados por perfilagem, sem a descrição geológica do furo CAL-14.
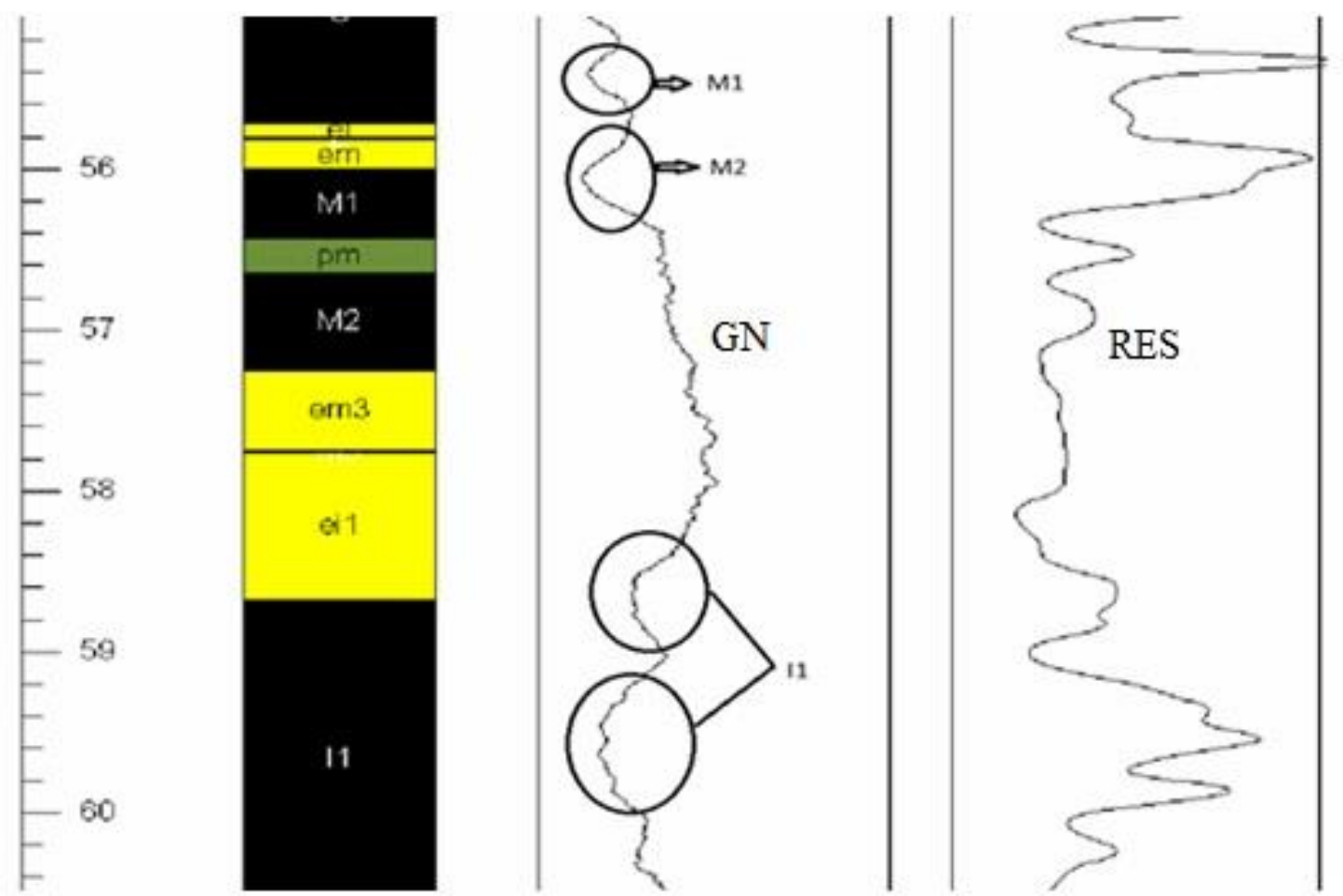

Figura 11 - Semelhança de assinaturas das camadas M1 e M2 com a camada I1 no mesmo perfil, dificultando o reconhecimento litológico na Área B3. 


\section{Banco de Dados}

O banco de dados é composto por furos sondados com recuperação de testemunho e perfilados com a sonda elétrica medindo parâmetros de gama natural e resistividade.

As análises dos perfis foram executadas de duas maneiras distintas assim expostas:

i) reconhecimento das assinaturas das camadas de carvão juntamente com a descrição geológica; ii) reconhecimento das assinaturas das camadas de carvão sem o auxílio da descrição geológica.

A tabela 1 mostra as áreas, a quantidade de furos e as camadas identificadas. Ressalta-se que nem todas as camadas estão presentes em todos os furos.

Tabela 1 - Banco de dados.

\begin{tabular}{|c|c|c|c|c|}
\hline ÁREA & NÚMERO DE FUROS & CAMADAS & $\begin{array}{l}\text { C/DESCR. } \\
\text { GEOLÓG. }\end{array}$ & $\begin{array}{l}\text { S/DESCR. } \\
\text { GEOLÓG. }\end{array}$ \\
\hline B3 & 11 & \multirow{2}{*}{$\begin{array}{c}\text { A1-A2-L-S-M1-M2- } \\
\text { M3-I1-I2 }\end{array}$} & \multirow[t]{2}{*}{$\mathrm{X}$} & \\
\hline B3 & 3 & & & $X$ \\
\hline CAL & 13 & \multirow{2}{*}{ M-S1-S2-S3 } & \multirow[t]{2}{*}{$\mathrm{X}$} & \\
\hline CAL & 3 & & & $\mathrm{X}$ \\
\hline CRN & 13 & \multirow{2}{*}{ M1-M2-S } & \multirow[t]{2}{*}{$\mathrm{X}$} & \\
\hline CRN & 3 & & & $X$ \\
\hline SVN & 7 & \multirow{2}{*}{$\begin{array}{l}\text { S6-S5-S4-S3-S2-A-BL- } \\
\text { CS-CI-I1-I2-I3-I4 }\end{array}$} & \multirow[t]{2}{*}{$\mathrm{X}$} & \\
\hline SVN & 3 & & & $\mathrm{X}$ \\
\hline
\end{tabular}

\section{ANÁLISES DE DADOS}

Para cada depósito abordado neste trabalho, foram feitos quatro tipos diferentes de análises, conduzidas da seguinte forma:

(i) Através de visualização direta no perfil, houve 0 reconhecimento dos estratos carbonosos, mensurando a sua espessura com apoio da descrição geológica dos testemunhos de sondagem.

Esse procedimento é importante para a definição da assinatura geofísica dos estratos e também será usado quando é desejável, por exemplo, verificar a espessura do estrato carbonoso em testemunho de sondagem com recuperação deficiente;

(ii) Através de visualização direta nos perfis, houve $o$ reconhecimento dos estratos carbonosos mensurando suas espessuras sem a utilização da descrição geológica dos testemunhos de sondagem.

Salienta-se que a descrição geológica dos testemunhos de sondagem, embora existente, foi usada somente para validar as interpretações e identificar os erros cometidos nesse procedimento, fornecendo uma ideia da acuracidade da perfilagem quando se deseja estimar espessura de carvão em furos perfilados em bancada de lavra, quando não há extração de testemunhos.
As análises (i) e (ii) acima foram feitas a partir de furos de sondagem com recuperação de $100 \%$ ou muito próximo disso, para garantir grande acuracidade na medida de espessura dos estratos de carvão a partir da descrição geológica.

Reconhecimento dos estratos carbonosos com apoio da descrição geológica nas áreas estudadas

Quanto à identificação dos estratos carbonosos contando com o apoio de descrições geológicas obtidas a partir do exame dos testemunhos de sondagens, os resultados são apresentados na tabela 2 para a Área B3, seguindo esse mesmo procedimento para as outras áreas.

\section{Reconhecimento dos estratos carbonosos sem o apoio da descrição geológica nas áreas estudadas}

A tabela 3 mostra os resultados obtidos no reconhecimento das camadas de carvão sem o apoio da descrição geológica feita a partir de testemunhos de sondagem.

\section{Resultados}

As tabelas 4 e 5 ilustram os dois métodos de avaliação, apresentando os percentuais de diferenças de espessura verificadas entre a descrição geológica e a perfilagem geofísica. Com 
o apoio da descrição geológica, somente Cerro e menores a $5 \mathrm{~cm}$ (Tabela 4). As demais situações Seival apresentam estimativas abaixo de $80 \%$ ficaram acima de $80 \%$, o que garante a viabilidade (65\% e 40\%) para diferenças entre a descrição de certificação da descrição geológica de uma geológica e a perfilagem geofísica iguais ou jazida com o auxílio da perfilagem geofísica.

Tabela 2. Reconhecimento dos estratos carbonosos com apoio da descrição geológica na Área B3.

\begin{tabular}{|c|c|c|c|c|c|c|c|c|c|}
\hline \multirow[b]{2}{*}{ Furo } & \multirow[b]{2}{*}{ Camada } & \multicolumn{3}{|c|}{ SONDAGEM } & \multicolumn{3}{|c|}{ PERFILAGEM } & \multirow{2}{*}{$\begin{array}{c}\text { Difer. } \\
\text { Abs. Esp (m) }\end{array}$} & \multirow{2}{*}{$\begin{array}{c}\text { Difer. } \\
\text { Rel. Esp (\%) }\end{array}$} \\
\hline & & De & Para & $\operatorname{Esp}(\mathbf{m})$ & De & Para & Esp (m) & & \\
\hline B3 - 12 & A1 & 27,50 & 27,65 & 0,15 & 27,28 & 27,45 & 0,17 & $-0,02$ & 13,33 \\
\hline B3 - 12 & A2 & 27,84 & 28,19 & 0,35 & 28,23 & 28,55 & 0,32 & 0,03 & $-8,57$ \\
\hline B3 - 12 & $\mathbf{S}$ & 38,95 & 39,95 & 1,00 & 38,95 & 39,95 & 1,00 & 0 & 0 \\
\hline B3 - 12 & M1 & 40,20 & 41,92 & 1,72 & 40,25 & 41,95 & 1,70 & 0,02 & $-1,16$ \\
\hline B3 - 12 & M2 & 42,42 & 43,12 & 0,70 & 42,5 & 43,23 & 0,73 & $-0,03$ & 4,29 \\
\hline B3 - 12 & I1 & 45,27 & 46,94 & 1,67 & 45,3 & 46,95 & 1,65 & 0,02 & $-1,20$ \\
\hline B3 - 18 & A1 & 49,60 & 50,56 & 0,96 & 49,30 & 50,30 & 1,00 & $-0,04$ & 4,17 \\
\hline B3 - 18 & A2 & 50,86 & 51,08 & 0,22 & 51,70 & 51,90 & 0,20 & 0,02 & $-9,09$ \\
\hline B3 - 18 & $\mathbf{S}$ & 61,82 & 63,47 & 1,65 & 61,70 & 63,38 & 1,68 & $-0,03$ & 1,82 \\
\hline B3 - 18 & M1 & 63,84 & 64,54 & 0,70 & 63,75 & 64,50 & 0,75 & $-0,05$ & 7,14 \\
\hline B3 - 18 & M2 & 64,88 & 66,30 & 1,42 & 64,80 & 66,20 & 1,40 & 0,02 & $-1,41$ \\
\hline B3 - 18 & I1 & 67,91 & 70,40 & 2,49 & 67,90 & 70,40 & 2,50 & $-0,01$ & 0,40 \\
\hline B3 - 18 & I2 & 73,00 & 74,20 & 1,20 & 73,05 & 74,35 & 1,30 & $-0,10$ & 8,33 \\
\hline B3 - 19 & A1 & 30,00 & 30,22 & 0,22 & $\bullet$ & $\bullet$ & $\bullet$ & $\bullet$ & $\bullet$ \\
\hline B3 - 19 & A2 & 30,40 & 31,40 & 1,00 & $\bullet$ & $\bullet$ & $\bullet$ & $\bullet$ & $\bullet$ \\
\hline B3 - 19 & $* \mathrm{~A} 1+\mathrm{A} 2$ & & $\Sigma$ & 1,22 & 30,15 & 31,40 & 1,25 & $-0,03$ & 2,46 \\
\hline B3 - 19 & $\mathbf{S}$ & 43,70 & 44,82 & 1,12 & 43,05 & 44,20 & 1,15 & $-0,03$ & 2,68 \\
\hline B3 - 19 & M1 & 45,05 & 45,78 & 0,73 & 44,55 & 45,30 & 0,75 & $-0,02$ & 2,74 \\
\hline B3 - 19 & M2 & 46,05 & 47,43 & 1,38 & 45,70 & 47,00 & 1,30 & 0,08 & $-5,80$ \\
\hline B3 - 19 & I1 & 50,63 & 52,28 & 1,65 & 49,50 & 51,20 & 1,70 & $-0,05$ & 3,03 \\
\hline B3 - 19 & I2 & 53,18 & 53,48 & 0,30 & 52,80 & 53,10 & 0,30 & 0 & 0 \\
\hline B3 - 21 & A1 & 50,05 & 51,44 & 1,39 & 49,30 & 50,70 & 1,40 & $-0,01$ & 0,72 \\
\hline B3 - 21 & $\mathbf{S}$ & 62,89 & 63,76 & 0,87 & 62,15 & 63,00 & 0,85 & 0,02 & $-2,30$ \\
\hline B3 - 21 & $\mathbf{L}$ & 64,00 & 64,27 & 0,27 & 63,20 & 63,45 & 0,25 & 0,02 & $-7,41$ \\
\hline B3 - 21 & M1 & 64,53 & 65,46 & 0,93 & 63,72 & 64,62 & 0,90 & 0,03 & $-3,23$ \\
\hline B3 - 21 & M2 & 65,62 & 66,12 & 0,50 & $\bullet$ & $\bullet$ & $\bullet$ & $\bullet$ & $\bullet$ \\
\hline B3 - 21 & M3 & 66,13 & 67,19 & 1,06 & $\bullet$ & $\bullet$ & $\bullet$ & $\bullet$ & $\bullet$ \\
\hline B3 - 21 & *M2 & & $\Sigma$ & 1,56 & 64,80 & 66,35 & 1,55 & 0,01 & $-0,64$ \\
\hline B3 - 21 & I1 & 69,33 & 72,39 & 3,06 & 68,45 & 71,48 & 3,03 & 0,03 & $-0,98$ \\
\hline B3 - 21 & I2 & 75,69 & 77,95 & 2,26 & 74,80 & 77,00 & 2,20 & 0,06 & $-2,65$ \\
\hline B3 - 50 & A1 & 48,70 & 48,98 & 0,28 & 47,80 & 48,10 & 0,30 & $-0,02$ & 7,14 \\
\hline B3 - 50 & A2 & 49,18 & 49,44 & 0,26 & 48,25 & 48,50 & 0,25 & 0,01 & $-3,85$ \\
\hline B3 - 50 & $\mathbf{S}$ & 61,71 & 62,61 & 0,90 & 60,90 & 61,80 & 0,90 & 0 & 0 \\
\hline B3 - 50 & $\mathbf{L}$ & 62,84 & 63,15 & 0,31 & 61,95 & 62,25 & 0,30 & 0,01 & $-3,23$ \\
\hline B3 - 50 & M1 & 63,53 & 64,28 & 0,75 & 62,60 & 63,30 & 0,70 & 0,05 & $-6,67$ \\
\hline B3 - 50 & M2 & 64,33 & 65,2 & 0,87 & 63,40 & 64,30 & 0,90 & $-0,03$ & 3,45 \\
\hline B3 - 50 & I1 & 67,60 & 68,17 & 0,57 & 66,70 & 67,30 & 0,60 & $-0,03$ & 5,26 \\
\hline & & & & & & & Diferença Média (m) & $-0,002$ & \\
\hline & & & & & & & Desvio Padrão (m) & 0,036 & \\
\hline
\end{tabular}

B3 - 19 *A1+A2 Não foi possível individualizar as camadas na perfilagem

B3 - 21 *M2 $\quad$ Não foi possível individualizar as camadas M2 e M3 na perfilagem 
Tabela 3. Reconhecimento dos estratos carbonosos sem apoio da descrição geológica na Área B3.

\begin{tabular}{|c|c|c|c|c|c|c|c|c|c|}
\hline \multirow[b]{2}{*}{ Furo } & \multirow[b]{2}{*}{ Camada } & \multicolumn{3}{|c|}{ SONDAGEM } & \multicolumn{3}{|c|}{ PERFILAGEM } & \multirow{2}{*}{$\begin{array}{l}\text { Dif. Abs. } \\
\text { Esp. (m) }\end{array}$} & \multirow{2}{*}{$\begin{array}{l}\text { Dif. } \\
\text { Rel. } \\
\text { Esp. } \\
(\%)\end{array}$} \\
\hline & & De & Para & Esp. (m) & De & Para & Esp. (m) & & \\
\hline B3 - 13 & A1 & 27,40 & 27,78 & 0,38 & 27,00 & 27,65 & 0,65 & $-0,27$ & 71,05 \\
\hline B3 - 13 & A2 & 27,91 & 28,18 & 0,27 & 28,02 & 28,30 & 0,28 & $-0,01$ & 3,70 \\
\hline B3 - 13 & $\mathbf{S}+\mathbf{L}$ & 40,02 & 41,48 & 1,46 & 39,70 & 41,25 & 1,55 & $-0,09$ & 6,16 \\
\hline B3 - 13 & M1 & 42,00 & 42,76 & 0,76 & 41,85 & 42,65 & 0,80 & $-0,04$ & 5,26 \\
\hline B3 - 13 & M2 & 42,98 & 44,48 & 1,50 & 42,88 & 44,38 & 1,50 & 0,00 & 0,00 \\
\hline B3 - 13 & *M3 & 45,44 & 45,51 & 0,07 & 45,37 & 45,52 & 0,15 & $-0,08$ & 114,29 \\
\hline B3 - 13 & I1 & 46,60 & 48,5 & 1,90 & 46,55 & 48,45 & 1,90 & 0,00 & 0,00 \\
\hline B3 - 14 & A1 & 30,95 & 31,12 & 0,17 & 30,12 & 30,32 & 0,20 & $-0,03$ & 17,65 \\
\hline B3 - 14 & A2 & 31,13 & 31,32 & 0,19 & 30,50 & 30,75 & 0,25 & $-0,06$ & 31,58 \\
\hline B3 - 14 & $\mathbf{S}$ & 42,39 & 43,37 & 0,98 & 41,70 & 42,70 & 1,00 & $-0,02$ & 2,04 \\
\hline B3 - 14 & M1 & 43,61 & 44,25 & 0,64 & 42,90 & 43,70 & 0,80 & $-0,16$ & 25,00 \\
\hline B3 - 14 & M2 & 44,60 & 45,89 & 1,29 & 43,90 & 45,00 & 1,10 & 0,19 & $-14,73$ \\
\hline B3 - 24 & A1 & 47,74 & 48,09 & 0,35 & 47,65 & 48,10 & 0,45 & $-0,10$ & 28,57 \\
\hline B3 - 24 & A2 & 48,39 & 48,59 & 0,20 & 48,25 & 48,45 & 0,20 & 0,00 & 0,00 \\
\hline B3 - 24 & $\mathbf{S}$ & 60,45 & 60,87 & 0,42 & 60,90 & 61,30 & 0,40 & 0,02 & $-4,76$ \\
\hline B3 - 24 & M1 & 62,86 & 63,56 & 0,70 & 62,00 & 62,80 & 0,80 & $-0,10$ & 14,29 \\
\hline \multirow[t]{3}{*}{ B3 - 24} & M2 & 63,80 & 64,95 & 1,15 & 63,00 & 64,20 & 1,20 & $-0,05$ & \multirow[t]{3}{*}{4,35} \\
\hline & & & & & & & Diferença Média (m) & $-0,047$ & \\
\hline & & & & & & & Desvio Padrão (m) & 0,094 & \\
\hline B3 - 13 & *M3 & \multicolumn{6}{|c|}{ Espessura da camada é inferior à resolução das sondas } & & \\
\hline
\end{tabular}

Tabela 4. Estimativas para as diferenças de avaliação de espessuras no reconhecimento com apoio da descrição geológica.

\begin{tabular}{c|c|c|c}
\hline Área & $\begin{array}{c}\text { Diferença } \\
\leq \mathbf{5} \mathbf{~ c m}\end{array}$ & $\begin{array}{c}\text { Diferença } \\
\leq \mathbf{1 0} \mathbf{~ c m}\end{array}$ & $\begin{array}{c}\text { Diferença } \\
\mathbf{1 5} \mathbf{~ c m}\end{array}$ \\
\hline B3 & $90 \%$ & $97 \%$ & $100 \%$ \\
\hline CAL & $82 \%$ & $96 \%$ & $96 \%$ \\
\hline CRN & $65 \%$ & $91 \%$ & $91 \%$ \\
\hline SVN & $40 \%$ & $80 \%$ & $90 \%$ \\
\hline
\end{tabular}

A presença de arenito na interface do carvão nas áreas do Cerro e Seival podem ser consideradas como um indicativo de diferenças maiores, visto que os perfis de gama natural e resistividade não discriminam bem este contato litológico.

Para análises das camadas de carvão sem o auxílio da descrição geológica, na tabela 5, é possível ter boas previsões para diferenças entre 10 e $15 \mathrm{~cm}$, principalmente na Área B3 e Calombo, as quais não sofrem a influência do arenito.

É importante salientar que com apoio da descrição geológica a identificação dos estratos carbonosos ocorreu em todos os casos, embora em algumas situações tenha havido dificuldade em individualizar camadas (p.ex. estratos A1/A2, em B3) ou estas foram identificadas somente por um dos perfis (gama natural ou resistividade, como na Área Cerro). Isso acontece quando o arenito está em contato com carvão, apresentando o mesmo sinal de gama natural e então somente é possível demarcar limites através do perfil de resistividade. Também vale salientar que na ausência de descrição geológica a discriminação no Cerro é quase impossível (Figura 12).

Tabela 5 - Estimativas para as diferenças de avaliação de espessuras no reconhecimento sem apoio da descrição geológica.

\begin{tabular}{c|c|c|c}
\hline Área & $\begin{array}{c}\text { Diferença } \\
\leq \mathbf{5} \mathbf{~ c m}\end{array}$ & $\begin{array}{c}\text { Diferença } \\
\leq \mathbf{1 0} \mathbf{~ c m}\end{array}$ & $\begin{array}{c}\text { Diferença } \\
\leq \mathbf{1 5} \mathbf{c m}\end{array}$ \\
\hline B3 & $53 \%$ & $82 \%$ & $82 \%$ \\
\hline CAL & $22 \%$ & $78 \%$ & $100 \%$ \\
\hline CRN & $38 \%$ & $50 \%$ & $63 \%$ \\
\hline SVN & $30 \%$ & $50 \%$ & $70 \%$ \\
\hline
\end{tabular}




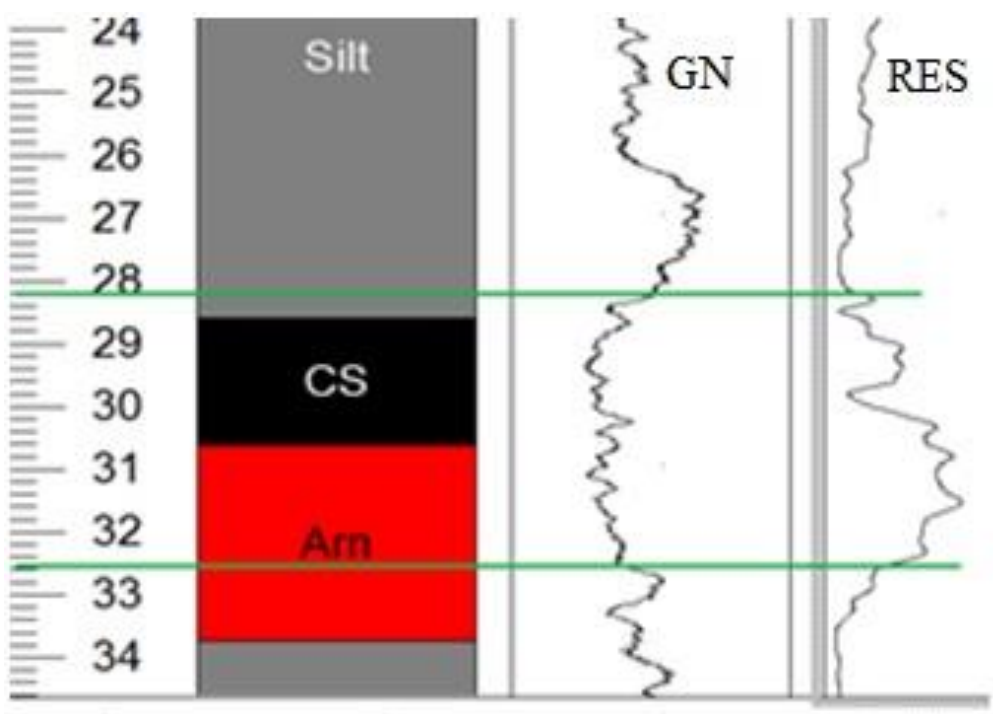

Figura 12. Impossibilidade de discriminar a camada de carvão S em relação ao arenito no perfil GN na Área do Cerro.

\section{CONCLUSÕES}

Este estudo investigou a possibilidade do uso da perfilagem geofísica de gama natural e resistividade na discriminação de estratos carbonosos, em relação a outras litologias presentes em quatro depósitos de carvão localizados no Rio Grande do Sul (áreas B3, Calombo, Cerro e Seival). A análise de diversos furos de sondagem realizados em cada depósito mostrou razoável similaridade de assinaturas geofísicas de estratos de carvão situados na mesma jazida. Isso faz com que seja possível na maior parte dos casos o reconhecimento litológico destes estratos baseado em perfis geofísicos de gama natural e resistividade.

Nas sondagens do depósito B3, por exemplo, tem-se a assinatura de duas camadas M1 e M2 muito características, não encontradas nos outros depósitos, fator que permite facilmente a identificação e a diferenciação com relação às demais.

No caso da jazida de Seival, duas camadas (Candiota Superior e Candiota Inferior) com espessuras bem superiores a quaisquer outras camadas presentes em outras jazidas tornam simples sua identificação.

No depósito do Cerro, a presença de arenito na interface com o carvão é um fator que caracteriza essa jazida. Ao mesmo tempo, gera extrema dificuldade para individualizar as camadas de carvão unicamente por perfilagem, algo que torna quase impossível a discriminação dessas camadas sem o auxílio da descrição geológica.

No depósito de Calombo, não foi observada nenhuma característica de semelhança em relação aos demais depósitos. Entretanto, dada a distribuição de estratos em termos de espessura e sequência de deposição, bem como a ausência de estratos com característica geofísica similar ao carvão (arenito), este foi o depósito que apresentou os menores valores de diferenças relativas, algo que facilitou na identificação das camadas de carvão.

$\mathrm{Na}$ situação onde há o apoio da sondagem com recuperação de testemunho, com uma diferença de até $10 \mathrm{~cm}$ na identificação por perfilagem geofísica e sondagem geológica, nas áreas B3 e Calombo ocorre mais de $90 \%$ dos estratos com diferenças abaixo desse valor. Nas áreas Cerro e Seival, esta diferença (de até $10 \mathrm{~cm}$ ) ocorre em mais de $80 \%$ dos estratos.

$\mathrm{Na}$ situação onde o reconhecimento é feito sem apoio da sondagem geológica, para diferenças menores ou iguais a $15 \mathrm{~cm}$, o percentual de reconhecimento está acima de $60 \%$.

\section{REFERÊNCIAS}

ANON. Guide to the Technical Evaluation of Higher Rank Coal Deposits. Australian Standard: Committee MN/1 Coal and Coke 1993, Australian Standard AS 2519, 1993.

ANON. Relatório de Atividades - Interno. GERÊNCIA DE MINERAÇÃO - COPELMI MINERAÇÃO Ltda., 2017.

BOND, L.O.; ALGER, R.P.; SCHMIDT, A.W. Well log interpretation in coal mining and rock mechanics. Soil Mech. Eng., Trans, 250:355-362, 1971.

BORSARU, M. \& ASFAHANIA, J. Low-activity spectrometric gamma-ray logging technique for delineation of coal/rock interfaces in dry blast holes. Applied Radiation and Isotopes, v. 65, n. 6, p. 748-755, 2007. 
GORELIK, B. Avaliação do Uso da Perfilagem Geofísica para Reconhecimento das Assinaturas e Estimativas da Qualidade do Carvão dos Depósitos do Rio Grande do Sul. Porto Alegre, 2014. 142 p. Dissertação de Mestrado em Engenharia, PPGEM - Escola de Engenharia, Universidade Federal do Rio Grande do Sul

HEARST, J.R.; NELSON, P.H.; PAILLETT, F.L. Well Logging for Physical Properties. $2^{\mathrm{a}}$ ed., John Wiley and Sons, Ltd., 2000. 483 p.

HOFFMAN, G.L.; JORDAN, G.R.; WALLIS, G.R. Geophysical Borehole Logging Handbook for Coal Exploration. Alberta (CAN), The Coal Mining Research Centre, 1982, $270 \mathrm{p}$.

KAYAL, J.R. \& DAS, L.K. A method of estimating ash content of coal from combined resistivity and gamma-ray logs. Geoexploration, v. 19, n. 3, p.193-200, 1981.

MILANI, E.J. Evolução tectono-estratigráfica da Bacia do Paraná e seu relacionamento com a geodinâmica Fanerozoica do Gondwana sul-ocidental. Porto Alegre, 1997. 225 p. Tese (Doutorado), Instituto de Geociências, Universidade Federal do Rio Grande do Sul.
WEBBER, T.; SALVADORETTI, P.; COSTA, J.F.C.L.; KOPPE, J.C. Estimativa de qualidade de carvão usando krigagem das indicatrizes aplicadas a dados obtidos por perfilagem geofísica. In: CONGRESSO BRASILEIRO DE MINA A CÉU ABERTO E CONGRESSO BRASILEIRO DE MINA SUBTERRÂNEA, V. Belo Horizonte. 2008. Anais...Belo Horizonte: IBRAM, p. 1-16,

WEBBER, T.; SALVADORETTI, P.; OLIVEIRA, L.J.; COSTA, J.F.C.L.; KOPPE, J. C.; CARVALHO FILHO, J.A.; BASTIANI, G.A. Estimativa de parâmetros indicadores de qualidade de carvão a partir de perfilagem geofísica - Mina do CERRO - Cachoeira do Sul/RS. In: CONGRESSO BRASILEIRO DE MINA A CÉU ABERTO E CONGRESSO BRASILEIRO DE MINA SUBTERRÂNEA, IV, Belo Horizonte, 2006. Anais... Belo Horizonte: IBRAM, p. 1-13.

Submetido em 10 de julho de 2017 Aceito em 24 de outubro de 2018 